\title{
An Empirical Review of English Language Teaching in Congo
}

\author{
Yvon-Pierre Ndongo Ibara ${ }^{1 *}$ \\ ${ }^{1}$ Modern Foreign Languages Department, Université Marien Ngouabi, Brazzaville, Congo \\ *Yvon-Pierre Ndongo Ibara, E-mail: yvon.ndongo-ibara@umng.cg
}

Received: September 15, 2016 Accepted: September 29, 2016 Online Published: October 7, 2016

doi:10.22158/selt.v4n4p400 URL: http://dx.doi.org/10.22158/selt.v4n4p400

\begin{abstract}
This contribution examines the pro and cons on the English language teaching practice in a non-English speaking country, Congo. It appears that English language is solely taught for examination purposes what is best summarized in terms of eye to read, think to write when the mouth remains shut. Oral communication is in a poor relation in language teaching and learning in Congo. One of the reasons is the inefficiency of the course of English phonetics and phonology at the Teachers Training College coupled with the lack of English linguistic background to prospective teachers.
\end{abstract}

Keywords

linguistics, language teaching and learning, language teachers, Congo

\section{Introduction}

English language has a long tradition in the teaching system of the Republic of Congo. Its teaching starts from grammar school as the second foreign language after French till high school and university. This study tends to sort our reasons justifying the non-speaking capabilities English learners lack even after seven regular years of learning. The aim of this paper is to review the way English language is taught in Congo in order to address the following questions: (1) what is the English language teaching method in Congo? (2) Do these methods enable Congolese learners to communicate in English? (3) Is linguistic background important to English language teachers?

\section{Methodology}

As primary data collection methods, questionnaire and exam papers for English language first year students were used to collect data for the completion of this piece of work. Based on the objectives of this study, questionnaire was administered to secondary school teachers of English in order to assess the reasons why English language teaching in Congo does not stress the relevance of teaching English language sound patterns to its learners the same way French learners start studying French with its sound patterns.

In addition, exam papers for English first year students were used for two reasons. Firstly, these papers 
help identify errors committed by undergraduate students in writing. In fact, this is to know whether linguistic instruments such as error analysis, discourse analysis, contrastive analysis are helpful enough to improve learners' understanding of English sound patterns. Secondly, this paper analysis tends to highlight the influence of the first foreign language (French) learnt by learners in such a way that French is taken as a default language system for writing and speaking English.

Finally, some other data were collected from research papers, books, and websites on the related issue.

\section{Foreign Language Teacher's Training}

Teachers of English for middle school and high school are mainly trained at the Teacher's Training School and a very few from Foreign Modern Department at the faculty of humanities and social sciences of our university. In the pre-service training, Middle school teachers have a three year training, whereas High school teachers follow a five year training. In fact, the curriculum for most English majors lay a particular attention on English language skill development. In (8), I show the learning hierarchy regarding the learning of foreign languages. Based on historical reasons, French is the first foreign language taught to students. English language learning starts at the first form of secondary school and continues throughout high school till the universities when other foreign languages are introduced at high school. The curriculum includes four basic skills (listening, speaking, reading, and writing) formulated as General Objectives and sub-skills are presented as Specific Objectives.

The French language teaching and learning is based on the books entitled Horizon d'Afrique from the first year of primary school and continues throughout the primary school till the first form of Middle school, the English language teaching has no specific books even though Go for English is the default choice. The success of French is historical since Horizon d'Afrique is used in all French speaking in the former French colonies in central Africa.

The in-service training for English teachers is almost absent in Congo. Many practicing teachers have been trained locally and had not benefited from a linguistic stay in an English speaking country. Inspectors are in charge of organizing these in-service programs, but their number is very limited to the extent that they are unable to achieve this task. In addition, the lack of coordination between inspectors and the Teacher Training College makes that the former are not aware of the evolutions resulted from research papers carried out by students in order to improve language teaching methods. So teachers and inspectors of English are the castoffs the society, they are abandoned to their fate. What is essential for them is to work as they can provided that they can prepare students to pass exams. In this respect, there are almost no seminars and discussions on language teaching, no recycled training for teachers. In addition, the country has no particular policy to strengthen teachers' capacity in the way it is done in other countries like China as commented below:

In addition to English language instruction from Chinese university teachers of English, they had been given a series of lectures by British specialists on topics in English language and literature. Much of the emphasis in this in-service program (as in most we learned about) was on the improvement of 
English language skills and on formal aspects of language and literature [...] Two television series on the topics of English phonology and English grammar had been produced jointly by the Shanghai municipal school board and a tertiary-level institution in that city. The programs attempted to assist English teacher-viewers to improve their English (Ronayne et al., 1979, p. 476).

When comparing the numbers of hours per week for learning English in Middle and High schools to the French ones, we will realize that those of English are lower than French. In general, the English curriculum is elaborated following the French model.

\section{First Foreign Language Teaching in Congo}

Our objective herein is to compare how Congolese learners are introduced to their first foreign language (FL1), French. As an ancient French colony, the Republic of Congo uses French as its official language. In addition to French, English is an obligatory second foreign language, whereas Chinese, Spanish, Arabic, Russian, German, and Portuguese are third optional foreign languages.

At primary school, the teaching of French starts with the identification and recognition of French sounds. The student is then introduced to the sound patterns of French. This aims at enabling the student to establish a link between the sign or symbol she/he sees on the board with its pronunciation.

(1) Teacher says: a: Students repeat the sound pronounced by the teacher

$$
\begin{aligned}
& \text { e, é, è, ê: } \\
& \text { i: } \\
& \text { o: } \\
& \text { u: } \\
& \text { b } \\
& \text { p } \\
& \text { t } \\
& \text { etc. }
\end{aligned}
$$

Following this step is the combination of these sounds to form syllables. In general, learners first acquire open syllables as follows:

$$
\text { a: ba }
$$$$
\text { e: be }
$$$$
\text { é bé }
$$$$
\text { è bè }
$$$$
\text { ê bê }
$$

b i: bi
o: $\quad$ bo
u: $\quad$ bu

Then a learner proceeds forward by combining these CV syllables to get CVCV forming words as illustrated in (3). 
(3)

a: ba, e.g., baba, oba, eba,

e: be, e.g., bel, bec

é bé, e.g., bébé

è bè, e.g., bègue

ê bê, e.g., bête

b i: bi, e.g., bibi, obi

o: bo, e.g., bobo,

u: bu, e.g., bubu

Once this step is mastered, another step in letter combination starts. That one concerns combining different consonants to get a cluster or different vowels as follows.

(4) a. Consonant $+1(r)$

ex. table, sable, crane

b. Vowels

ex. au/eau

The last step in showing and teaching letter-sound pronunciation is the recognition of homophones which in one way or another is connected to grammar. The initiation to French grammar starts as simpler as possible. Learners start by distinguishing for example a/à, ce/se, on/ont, son/sont, etc.

(5) a. Ce bébé pleure.

This kid cries

b. L'enfant se lave.

A kid has a bath

c. Ce bébé a un bonbon.

This kid has a candy

d. Papa est à la maison.

Dad is at home

e. On ne parle pas à table.

We do not talk at the table

\section{f. Ils ont faim.}

They are hungry

g. Son père et sa mère sont à la maison.

His/her father and his/her mother are at home

Only then can the reading of text starts. It looks like the learner is emerging with the language as a seed comes out of the sand after conditions of germination are met. They are growing with the language they are learning. 


\section{English Language Teaching in Congo}

This section is devoted to the methods teachers use in order to teach English language in Congo. Many teachers of English concentrate on the following issues: English grammar, reading comprehension, language functions.

Prior to this analysis, it is worth stating that the teaching method used in the Republic of Congo is mainly the Grammar Translation Method. In the introductory part of Go for English (Note 1) we can read "Go for English combines the best features of traditional methodology". In the words of Diane Larsen-Freeman (2000, p. 15), a fundamental purpose of learning a foreign language is to be able to read literature written in it. Literary language is superior to spoken language. Students' study of the target culture is limited to its literature and fine arts.

In this connection, English as an L2 is not primary taught for spoken communication, but rather for written purpose. This is the reason why the teaching-learning is summarized in the memorization and application of grammatical rules, reading comprehension and related exercises, writing a composition.

The study of English grammar deals with syntactic aspects of the language. This is important to help students know the different distributional properties of words in English in order to help them write a guided writing (F4 (Note 2)) or a composition (Upper sixth form). In the introduction of English for French-Speaking Countries, Enjoy Learning English 5e (Note 3), we can read "Basically, the goal is to check and extend students' capacity to use English grammar". This concerns conjugation, agreement, sentence form, tense, voice, comparison, speech, parts of speech, etc. The presentation of grammar courses is based on a structural analysis as follows:

Table 1. A Grammar Lesson Presentation

\begin{tabular}{|c|c|c|c|}
\hline \multicolumn{4}{|c|}{ Present tense of ordinary verbs in English } \\
\hline Subject categories & Affirmative form & Negative form & Interrogative form \\
\hline \multirow[t]{3}{*}{$1_{\mathrm{st}}, 2_{\text {nd }}$ singular } & $\mathrm{S}+\mathrm{V} \_\phi+\mathrm{O}$ & $\mathrm{S}+\mathrm{do}$ not $+\mathrm{V}+\mathrm{O}$ & $\mathrm{Do}+\mathrm{S}+\mathrm{V}+\mathrm{O} ?$ \\
\hline & I learn English & I do not learn English & Do I learn English? \\
\hline & You learn English & You do not learn English & Do you learn English? \\
\hline \multirow[t]{3}{*}{$1_{\mathrm{st}}, 2_{\mathrm{nd}}, 3_{\mathrm{rd}}$ Plural } & $\mathrm{S}+\mathrm{V}_{-} \phi+\mathrm{O}$ & $\mathrm{S}+\mathrm{do}$ not $+\mathrm{V}+\mathrm{O}$ & $\mathrm{Do}+\mathrm{S}+\mathrm{V}+\mathrm{O} ?$ \\
\hline & We/you/they learn & We/you/they do not learn & Do We/you/they learn \\
\hline & English & English & English? \\
\hline \multirow{6}{*}{$\begin{array}{l}3_{\text {rd }} \text { Sing or Sing } \\
\text { subjects }\end{array}$} & $\mathrm{S}+\mathrm{V} \_\mathbf{s}+\mathrm{O}$ & $\mathrm{S}+$ does not $+\mathrm{V}+\mathrm{O}$ & Does $+\mathrm{S}+\mathrm{V}+\mathrm{O} ?$ \\
\hline & He learns English & He does not learn English & Does he learn English? \\
\hline & $\mathrm{S}+\mathrm{V} \_$es+ O & $\mathrm{S}+$ does not $+\mathrm{V}+\mathrm{O}$ & Does $+\mathrm{S}+\mathrm{V}+\mathrm{O} ?$ \\
\hline & She washes dishes & She does not wash dishes & Does she wash dishes? \\
\hline & $\mathrm{S}+\mathrm{V} \_$ies $+\mathrm{O}$ & $\mathrm{S}+$ does not $+\mathrm{V}+\mathrm{O}$ & Does $+\mathrm{S}+\mathrm{V}+\mathrm{O} ?$ \\
\hline & Tom studies English & Tom does not study English & Does Tom study English? \\
\hline
\end{tabular}


The students are asked to memorize the different structures. To reinforce their learning, teachers can choose to give sentences with a scramble order asking them to re-arrange these words in order to get good sentences.

\section{Grammar exercises}

a- $\quad$ Re-order the words to make correct sentences.

1- She/letter/me/wrote/a/.

2- New/him/father/a/bought/his/pen/.

3- Sold/us/a/he/paw-paw/.

4- Them/presents/I/brought/.

b- Change your sentence into questions.

Ex: Did she write me a letter (Go for English, 5e, p. 31)?

In addition to grammar course, there is reading comprehension which is based on the study of literary texts selected according to the different themes that are listed in the curriculum. In the foreword of l'Anglais en Afrique et à Madagascar, we note:

A large number texts are based on western culture ... questions on the text do not only concern elucidation and comprehension; students are regularly asked to think about one particular aspect of the text (Note 4).

Most texts describe western culture and very few talk about African realities. When studying a text, students are provided with a piece of text, the teacher selects some words randomly to be studied. Teachers randomly select some words from a text, they can sometimes provide their transcriptions, a translation of the so-called "difficult words" is given either in French or an explanation in English. There is no further exercise or activities that help students use the learnt vocabulary. This vocabulary has no reinforcement exercises. That is to say, none of the words whose translations are provided are not used in further tasks, leading to a demotivation to learning these new words. In other words, Congolese do not know how to teach a vocabulary in such a way that students can benefit from word list. Furthermore, when practicing one of the exercise related to vocabulary namely blank filling the list of words given is totally different from that of difficult words previously learned during the comprehension of a text. This means that vocabulary in Congo is still "a poor relation" (Maiguascha, 1993) or a "neglected aspect in language learning" (Maera, 1980, 2002) in English language teaching and learning. In this respect, Wilkins argues that:

There is not much value in being able to produce grammatical sentences if one has not got the vocabulary that is needed to convey what one wishes to say ... While without grammar very little can be conveyed, without vocabulary nothing can be conveyed (Wilkins, 1972, pp. 110-111).

Further to Wilkins' assertion, we are convinced that the Congolese teachers of English focus on grammar is a proof justifying why learners are unable to communicate in English because they do not have the adequate vocabulary. This is due to the fact that vocabulary learning is an individual quest students' adventure alone. Oxford and Scarcella (1994, p. 231) assume that "students are usually 
expected to learn vocabulary on their own without much guidance". The lack of considerable teaching strategies leads vocabulary learning challenging and unsuccessful.

In addition, after the vocabulary listing, there is a list of questions for the general understanding of the text. From F1 to the Upper Sixth form, students deal with True, False, Not in the text, Matching-up or conversational exchange, blank filling, guided writing for F4 and composition for the Upper sixth form. It appears that students are trained in such a way that they are getting ready to pass an exam, but no to use the language for verbal communication.

It has been assumed that while learning French language, students immerse with the language as they firstly acquaint themselves with the sound system of the target language. So can we talk the same story with English language learning?

The answer to this question is absolutely no. The learners at F1 in grammar school starts their first English course by language functions. That is, since their first contact with English, learners are not introduced to the sound patterns of English, even more to letter combination procedure, but rather to greetings, introductions, feelings...

(6) Greetings: Good morning, good afternoon, good evening, good night, Hello, Hi.

Feelings: How are you? Fine, thanks.

Introduction: What is your first/last name?

Naming things: What is this/that?

Some teachers, aiming to bridge the gap between the letters and their pronunciation, teach alphabet in English.

\section{Aa Bb Cc Dd Ee Ff Gg Hh Ii Jj $\mathrm{Kk}$ Ll $\mathrm{Mm}$

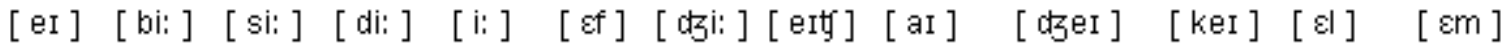 Nn Oo Pp Qq Rr Ss Tt Uu Vy Ww Xx Yy Zz

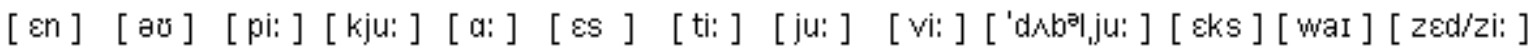

Figure 1. Alphabet

Under these circumstances, it is undoubtedly obvious that Congolese learners will encounter difficulties in coping with this second foreign language sound patterns. When teaching the greetings, the word "good" is used and pronounced as follows [god] but after the teaching of the alphabet we have: g[dzi:] o[ov] d[di:]. So, there is no connection between the teaching of the alphabet and the pronunciation of the word.

Further to this alphabetic teaching, students are confused and preferred to read silently than to speak. In order to understand the reasons underpinning the non-teaching of English sound patterns following the French way in primary school, we asked the following question to teachers: Why don't you teach English sound patterns the way French letters are taught in primary school? The answers are 
summarized in Table 2 below:

Table 2. Teachers' Answers

\begin{tabular}{lll}
\hline Question & \multicolumn{2}{l}{ Teacher's answers } \\
\hline Why don't you teach & - & Pupils we teach are supposed to master sounds in general \\
English sounds the way & - & English alphabet lesson better the English letter sound to pupils \\
French sounds were taught & - & English words are not pronounced the same way like in French \\
in primary school? & - & There is a gap between sounds and spelling in English \\
& - & This technique is not included in our program \\
\hline
\end{tabular}

From the teachers' explanation, we observe that the teaching of English sound patterns is based on a "presupposition" or a "prerequisite". That is to say, owing to the fact English and French use the same written symbols that represent the different letters used in the languages, teachers of English think that the primary school teaching of French is sufficient. In addition, this conviction is reinforced by their choice in teaching the English alphabet, which they think would better the understanding of the English letter.

It should be highlighted that if the French letter connection to their corresponding sounds is straight forward, that of English is amazingly strange. To quote Nambiar (2009, p. 1) "English does not have a spelling pronunciation, i.e., there is no one-to-one correspondence between the letters of English alphabet and the sounds that they represent in different words". This is due certainly to the history of English language words that have different language sources such as Latin, French, German, to quote but a few. Some teachers are aware of the fact that "English words are not pronounced the same way like in French. There is a gap between sounds and spelling in English". This means that resorting to the French pronunciation when speaking English is misleading. As a result, teachers should provide students with English sound course in order to sharpen their awareness on this issue.

The last concern is about the institutional responsibility. For some teachers, INRAP, the technical body for curricula design did not mention the teaching of English sounds. This viewpoint is wrong because in the English curriculum we have "sound discrimination, stress, intonation" in General objective 2 in the English secondary school syllabus.

Yet, the responsibility lies with the Teacher Training College where the didactics course is not properly carried out. In fact, during their training at Teacher Training College, teachers are not initiated and trained to the teaching of sounds. In other words, teachers' trainers failed, in the past, to transpose phonetic knowledge from scientific to pedagogical; they taught sounds description based on articulatory phonetics. Under this condition, prospective teachers are trained as phoneticians, but not teachers because the latter will not describe English sounds in terms of place/manner of articulation, the relevance of the glottis for distinguishing voiced from voiceless sounds or the soft palate for oral and 
nasal sounds, but they are going to explain learners the whys such a letter or a combination of letters is differently pronounced. Once this didactic transposition fails, the learners are unable to practice from what they are taught.

In addition, some books used for the teaching of English such as L'Anglais en Afrique, English for French Speaking Countries, Go for English to quote but a few, do not provide teacher with helpful hints to work out this issue. This is one of the reasons why they confuse between teaching a sound and transcribing a sound. In this connection, it is important to mention that teaching means explaining why this is like that, whereas transcribing is copy and paste.

Finally, teachers of English confuse between transcriptions of words taken from a text, reading aloud in the class with teaching English pronunciation. When transcribing a sound, students are not exposed to the whys for example /a/ is pronounced [ei] in "cake", [a:] in "car", [æ] in "cat", [ə] in "about", [॰:] in "tall" but [i] in "cabbage". There is no comment nor explanation accounting for a given transcription, what is a must when teaching a sound. Finally, as teachers do not have a book covering issues about English sound teaching, they think that it is hazardous for them to adventure in sound teaching. For they do not know the way to cope with this issue following a teaching card presentation.

However, if Congolese teachers of English skip the teaching of the pronunciation of sounds, sound combination, but prefer to start at the word level, I think that this is the wrong way to teach a foreign language. Abbas Pourhosein Gilakjani (2012, p. 119) is right when stating that pronunciation "is an integral part of foreign language learning since it directly affects learners' communicative competence as well as performance". Linguistically speaking, a word represents at least the third level of hierarchy in language process, namely the sound, the syllable, the word.

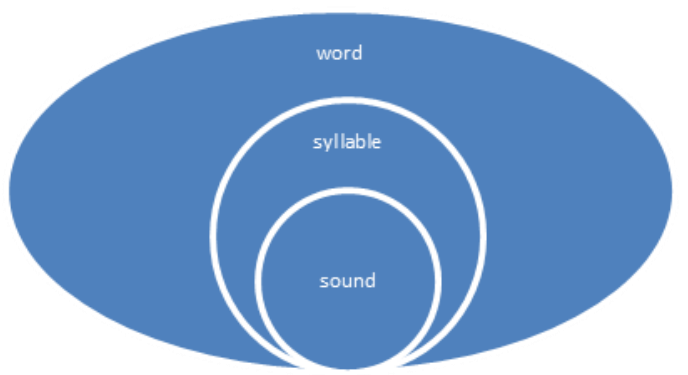

Figure 2. Word Internal Hierarchy

Under phonetic and phonological considerations, each layer of a word is differently affected by phonological rules which are languages specific. In English for example, sounds are differently pronounced according to neighbouring sounds (7a), syllables are sometimes shortened (7b) and words are sometimes weak or strong (Table 3).

(7a) car [ka:], care [keə], talk [to:k]

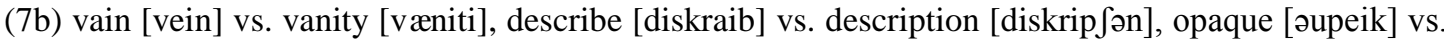
opacity [əupæsiti] 
Table 3. Weak and Strong of Words

\begin{tabular}{|c|c|c|}
\hline & Strong form usage & Weak form \\
\hline \multirow{3}{*}{$\begin{array}{c}\text { a/an }[\mathrm{ei}] /[\text { æn }] / \\
{[ə] /[ə n]}\end{array}$} & For showing a contrast. & Before a consonant and a vowel. \\
\hline & This is a solution, but not the only one. & This is a solution. \\
\hline & This is an ideal, but it is not the ideal. & This is an ideal. \\
\hline \multirow{2}{*}{ that [ðæt]/[ðət] } & When used as a demonstrative pronoun & When used as a relative pronoun. \\
\hline & I like that one. & I said that I am broke. \\
\hline \multirow{2}{*}{ but $[\mathrm{b} \Lambda \mathrm{t}] /[\mathrm{b} \partial \mathrm{t}]$} & For showing a contrast. & When used as a coordinator \\
\hline & Your son is but crazy. & Your son is here, but mine is at school. \\
\hline \multirow{2}{*}{ from $[$ from $] /[$ frəm $]$} & For showing a contrast or end position. & When expressing location indication. \\
\hline & Going to or from BZV/Where are you from? & He is from BZV. \\
\hline Some & When used as a quantifier. & When used as a determiner. \\
\hline$[\mathrm{s} \Lambda \mathrm{m}] /[\mathrm{s} ə \mathrm{~m}]$ & Some are here. I want some. & I saw some people. \\
\hline \multirow{2}{*}{ Your [jo:r]/[jə] } & When used for emphasis or contrast. & When used as a possessive pronoun. \\
\hline & It's your fault. With your looks and my brain. & Take your time. \\
\hline \multirow{2}{*}{ you [ju:]/[ju/jə] } & For emphasis, contrast. & Ordinary subject or object. \\
\hline & Will it be you or me? It was you that broke it. & If you can. Thank you. \\
\hline
\end{tabular}

In this respect, if one does not master the pronunciation of the sound, that of the syllable or sound combination, the pronunciation of a word becomes really a big challenge. Roland Ondze Otouba (2016) writes "to appropriate a new language pronunciation concerns a process implying a linguistic, physical awareness, what makes the student develop his/her auditory sharpness". That is to say, when a learner is familiarized with the pronunciation of the second language, this raises his/her a linguistic, physical awareness that leads to develop his/her auditory capacity. This capacity is important for speaking a language.

Under Congolese context, the learner is condemned to learn because he is forced to do so to get grades, but $\mathrm{s} / \mathrm{he}$ is aware that pronunciation that can encourage him/her to say something is not the teacher's interest. This can justify why the teacher has never ever attempted to incorporate pronunciation among items of English course assignments.

Finally, all along the secondary education, students learn language functions including communicative speech acts. These functions refer to greetings, introductions, expressing feelings, one's opinion, agreement and disagreement, describing. It appears that greetings and introductions are amongst the notions that are kept for long by most Congolese learners. The environment, the inadequacy of the vocabulary teaching methods, the lack of true phonetic courses and the teaching methods are the fundamental causes entailing Congolese students' inability to perform efficient conversations in English. With regard to Grammar Translation method, Diane Larsen-Freeman (2000, p. 16) concludes 
that "The communication in the learnt language is not a goal for foreign language instruction". So, I put forward the idea that the aim of English language teaching in Congo is best summarized in terms eye to read, think, finally write when the mouth remains shut. Putting things in quite the same way, students are trained to fulfil reading and writing tasks, but listening and speaking tasks remain neglected. This can now justify why after eight years of learning almost all Congolese students can read, understand, reply based on text reading, but they almost all fail to communicate without a text. This point is also obvious from the introduction of Go for English (Note 4) 5e "This course will help you to communicate in English. It will also help you to pass your examination in the future". The communication purpose is one side based on written language.

\section{Linguistics and Foreign Language Teaching}

This section is further to the question asked to Congolese English language teacher on the relevance of a linguistic background to their training. Under world based analysis, linguistics has helped improve language teaching in terms of contrastive analysis, error analysis, discourse analysis and universal grammar. The goal of this section is twofold. Firstly it provides a review of some previous works and shows errors committed by students as the result of poor teaching methods. The other reason is to highlight the different skills these linguistic instruments help develop.

Fachun Zhang and PengPeng Yi (2009) deal with English pronunciation driving data from Chinese environment. They argue that the misunderstanding of the phonological system of each language in contact during a learning process leads to pronunciation problems. They argue that:

Some Chinese students tend to have difficulty with English sounds because they are deeply influenced by similar Chinese sounds. However, they are very different from each other. A particular sound which does not exist in the native language can therefore pose a difficulty for the second language learners to produce or some times to try to substitute those sounds with similar ones in their mother tongue. These sounds include both vowels and consonants (Zhang \& Yi, 2009, p. 142).

They conclude that "the presentations of distinctions between Chinese and English phonological systems may raise our awareness of the differences of the two sound systems to avoid errors in pronunciation" (op.cit., p. 146).

Yayasundara and Premarathna (2001) examine errors committed by Sri Lanka undergraduate students. They assume that most students' errors in writing and speaking are due to their poor knowledge of English grammar. They observe that "Grammar being the most critical factors where undergraduates commit most of the errors in both the writing and speaking performances".

Mahsa Hariri (2012, p. 4857) carries a study on Iranian learners' errors with a particular emphasis on morpho-syntactic fieldwork. Here is the finding of his contribution. 


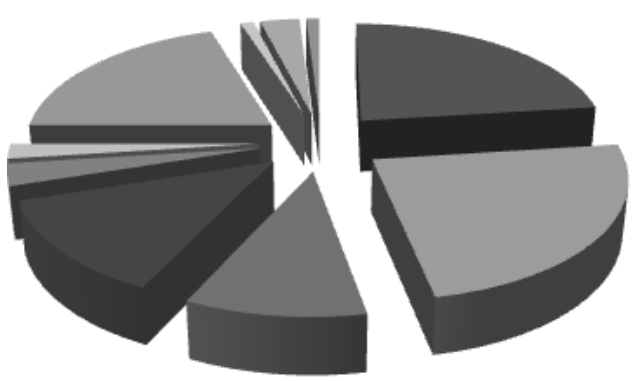

\author{
Errors in the use of articles \\ Errors in the use of prepositions \\ - Wrong word order \\ - Errors due to lack of concord \\ - Wrong use of conditional sentences \\ - Typical Persian constructions \\ Wrong use of tenses
}

Figure 3. Morphosyntactic Errors

The morphosyntactic analysis of errors shows a strong influence of L1 upon L2. This had also been the case study carried out by Noor (1996) on Arabic learners. These errors result from a transfer of L1 information to L2 during the acquisition as best shown in the following chart (op.cit, p. 4857).

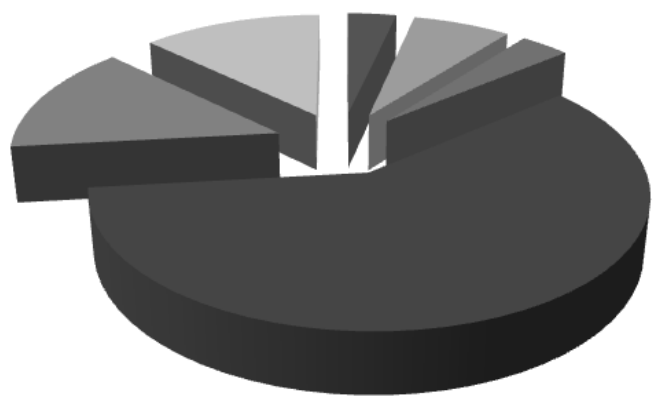

- Transfer of Grammatical elements

Transfer ofLexico-semantic elements

Transfer of Stylistic and Cultural elements

- Intralingual Errors

- Language Learning Strategies

Communication Strategies

Figure 4. L1 to L2 Information Transfer

The contrastive, error or discourse analysis puts priority on written language. This kind of analysis compares learners' performances in the L2 in order to highlight differences that lead to error production. In the ensuing lines, first year students' exam papers are examined in order to highlight students' errors.

Table 4. Students' Spelling Errors

\begin{tabular}{lll}
\hline & Spelling errors & Appropriate form \\
\hline A12 copy reference & $\ldots$ quiet well & $\ldots$.quite well \\
A21 copy reference & $\ldots$ lawer & $\ldots$.lower \\
A23 copy reference & $\ldots$ sintax & $\ldots$.syntax \\
A29 copy reference & $\ldots$ diny & $\ldots$ deny \\
A30 copy reference & $\ldots$ type of tongue & $\ldots$ tip of tongue \\
A41 copy reference & $\ldots$.rouls & $\ldots$.rules \\
A133 copy reference & $\ldots$..phoneticly & $\ldots$ phonetically \\
\hline
\end{tabular}

It comes out from these English first year students' copies that some errors show the influence of the 
French (L2) pronunciation on English (L3) language in (A30, A41), some illustrate that students write words the way they are pronounced in English (A23, A29, A133), some others are related to homophony (A12, A21). While correcting these errors, we tend to reinforce more learners' written capability than speaking ability as the latter will give rise to other associated complex issues.

Table 5. Students' Grammatical Errors

\begin{tabular}{lll}
\hline & Grammatical errors & Appropriate form \\
\hline A19 copy reference & $\ldots$ modern linguistics don't take... & $\ldots$..modern linguistics does n't take... \\
A71 copy reference & $\ldots$ the way where... & $\ldots$.the way how... \\
& $\ldots$ the writers were did their best... & $\ldots$..the writers had done their best \\
A98 copy reference & $\ldots$ grammar things was old... & $\ldots$. grammar things were old... \\
A118 copy reference & $\ldots$ the history of linguistics are... & $\ldots$..the history of linguistics is... \\
A139 copy reference & $\ldots$..it obeys in rules... & $\ldots$ it obeys rules... \\
\hline
\end{tabular}

The examples in Table 5 highlight students' poor understanding of English grammar. They have problem in processing proper agreement between the subject and the predicate. In (A19, A118) the students failed to know that the letter "s" which is attached to the word "linguistics" does not stand for plurality, but rather for singular nouns of sciences. Yet in (A98), the students consider the core word "grammar" as a subject ignoring that here it is used as an adjective. In (A71) and (A139), the students are using their L2 grammar and paste it in English. In fact, if in French "to obey" is a prepositional verb, hence selecting a postposition as the student did, in English, on the contrary, that verb does not select a postposition. Similarly, if in French, the word "où" has only on morphological form despite its various usages, in English its translation depends on its antecedent "the place where", "the time when", etc. Once again, we are here dealing with issues that have a straight connection to writing skills.

Table 6. French English Vocabulary Interference

\begin{tabular}{lll}
\hline & Vocabulary & Appropriate form \\
\hline A10 copy reference & $\ldots$ in clear & $\ldots$. in plain language, plainly \\
A154 copy reference & $\ldots$ for against... & $\ldots$..on the other hand, ... \\
copy reference & $\ldots$ was many concentrated... & $\ldots$..was mostly concentrated... \\
\hline
\end{tabular}

In Table 6, the students is writing English in French language. This is a proof of glossary translation of words from French to English: "en-in", "clair-clear", "par-for", "contre-against", "beaucoup-many". The students are transposing their French vocabulary in English, just as copy and paste.

When one tries to compare these students' errors, it comes out that the learning of English language by Congolese learners does not show the link between Congolese mother tongues and English, but rather 
illustrates the relationship between the first language learnt at school, i.e., French and English. This is a little bit different with what is stated by Wilkins (1972, p. 199) who observes that:

When learning a foreign language an individual already knows his mother tongue, and it is this which he attempts to transfer. The transfer may prove to be justified because the structure of the two languages is similar, in that case we get "positive transfer" or "facilitation"-or it may prove unjustified because the structure of the two languages are different in that case we get "negative transfer" —or interference (Wilkins, 1972, p. 199).

In fact, the linguistic situation in Congo is a kind of a quarter layer which looks like the following:

(8) L1: mother tongues

L2: French language

L3: English language

L4: Other foreign languages (Arab, Chinese, German, Portuguese, Russian, Spanish)

In the Congolese education system, only L2 and L3 are obligatory languages whilst L4 are optional languages. Under this condition, it means that the "negative transfer" between L1 and L2 concerns the learning of the French language. As a matter of fact, whence French language has been learned, the learning of another foreign language is undoubtedly influenced by its grammar as confirmed by these learners' errors. Following Laurell (1987) taxonomy on error analysis, we can assert that those students' errors are either lexical interference (A10, A154), interlingual phonological interference from French to English (A23, A41), and developmental interference related to morphology and particularly concord of agreement and past participle forms of verbs (A98).

In this connection, contrastive analysis or error analysis will be helpful to develop students writing skills by providing useful reinforcement courses to correct grammar. Yet lexical interference is due to the fact that English vocabulary is poorly taught.

This paper follows Zhang and Yi (2009) to the extent that it aims to highlight the great value of training teachers in the phonology of English in order to help them know how to teach English pronunciation. In fact, I totally agree with Louis Porcher quoted by Molina Mejía when he writes about phonetics:

For non-specialists, phonetics is an arduous science, intimidating for its technical aspects. People hope to learn how to use it, but they do not pretend to understand it profoundly. Considered as a difficult and relevant topic, phonetics has succeeded to keep its particular role in didactics: now subordinate, never minor. Dreadful, fascinating, it is pedagogically and sociologically like philistine to students and embodied in one of the most valuable aspect of language practice: pronunciation (Molina, 2007, pp. 4-5).

This proves that we could not have a good and fruitful language learning and teaching without a phonetic course since this course represents the sesame of the target language. In this connection, phonetic course on English sound patterns and prosody should be taught the same way grammar notions are taught to students. These courses make students aware of English language peculiarities regarding its sounds, stress, intonation, and grammar. An attempt in this regard has been carried out by 
Ndongo Ibara (2015), Ondze (2016) wherein English sound teaching has been experimented with Lower sixth form students. It appears that once this course is acquired by students, teachers will no longer be obliged to write whole lessons on the board, but they can dictate their course because students are already familiarized with English sound patterns.

\section{Conclusion}

This paper has been concerned with the way foreign languages are taught in Congo with a particular attention on English language. It highlights the hurdles that hinder successful learning of English. Compare to French language teaching, it appears that Congolese students are well trained in French since they learn both its sound patterns and grammar, but their learning is distorted in English where emphasis is only put in grammar, neglecting English sound patterns and prosody. In fact, the English language is taught in such a way that the students are trained to read texts in order to pass tests and exams without being able to perform oral communications. This long lasting English language practice in Congo is due to the fact that the teaching of English phonetics and phonology at the Teacher Training College is considered a "poor relation" or a neglected course in language teaching/learning. Teachers' trainers put forward the idea that phonetics is "devilish" or a "hanging juge" so they do not want to face all the hassles of teaching this course. In this respect, I find it hard to believe that we should let this go ahead because the English syllabus includes phonetic issues. It is very important for language teachers to have a strong command on the linguistic background of the target language so that they can properly train students because after having being learners, they will have to use the target language in their professional life.

\section{References}

Cowan, R. et al. (1979). English Teaching in China: A Recent Survey. TESOL Quarterly, 13(4), 465-482. http://dx.doi.org/10.2307/3586442

Hariri, M. (2012). Taxonomy of Morpho-Syntactic Errors and Error Analysis. Research Journal of Applied Sciences, Engineering and Technology, 4(22), 4856-4860.

Larsen-Freeman, D. (2000). Techniques and Principles in Language Teaching. Oxford: OUP.

Laurel, G. C. (1987). Contemporary Linguistic Analysis: An Introduction.

Maiguashca, R. (1993). Teaching and learning vocabulary in a second language: Past, present, and future directions. Canadian Modern Language Review, 50, 83-100.

Meara, P. (1980). Vocabulary acquisition: A neglected aspect of language learning. Language Teaching and Linguistics Abstracts, 13, 221-245. http://dx.doi.org/10.1017/s0261444800008879

Meara, P. (2002). The rediscovery of vocabulary. Second Language Research, 18(4), 393-407. http://dx.doi.org/10.1191/0267658302sr211xx

Molina, M., \& Jorge, M. (2007). Diagnostique et correction des erreurs de prononciation en FLE des apprenants hispanophones. Mémoire de Master. Université Stendhal-Grenoble 3. 
Nambiar, K. C. (2009). Speaking Accurately: A Course in international communication. New Delhi: Cambridge University Press India Pvt Ltd.

Ndongo, I., \& Yvon-Pierre. (2015). Framing English sound-letter parallelism teaching. Liens Nouvelle Série, 20, 37-47.

Noor, H. H. (1996). English Syntactic Errors by Arabic Speaking Learners: Reviewed. Saudi Arabia: King Abdulaziz University.

Ondze, O., \& Roland, G. (2016). L'enseignement de la prononciation des voyelles simples anglaises dans les classes de première au Congo (Unpublished Master's thesis). ENS, Brazzaville, Congo.

Oxford, R., \& Scarcella, R. (1994). Second language vocabulary learning among adults: State of the art in vocabulary $\quad$ instruction. $\quad$ System, 231-243. http://dx.doi.org/10.1016/0346-251X(94)90059-0

Pourhosein, G. A. (2012). A Study of factors Affecting EFL learners' English Pronunciation learning and Strategies for Instruction. International Journal of Humanities and Social Science, 2(3), 119-128.

Wilkins, D. A. (1972). Linguistics in Language Teaching. London: Edward Arnold.

Yayasundara, J. M. P. V. K., \& Premarathna, C. D. H. M. (2011). A linguistic analysis on errors committed by undergraduate students. International Journal of Scientific and Research Publications, 1, 1-6.

Zhang, F. C., \& Yin, P. P. (2009). A Study of Pronunciation Problems of English Learners in China. Asian Social Science, 5(6), 141-146. http://dx.doi.org/10.5539/ass.v5n6p141

\section{Notes}

Note 1. Kenneth, C. et al. (1993). Go for English 3è. London: MacMillan.

Note 2. French/English level system: (6e)F1, (5e)F2, (4e)F3, (3e)F4, Seconde (Fith form), Premiere (Lower sixth form).

Note 3. David, M. et al. (1986). English for French-Speaking Countries, Enjoy Learning English 5 e. Paris: Armand Colin-Longman.

Note 4. Bouet, J. (dir). l'Anglais en Afrique et à Madagascar, Classe de 3e (p. 3). Paris: Hatier.

Note 5. Kenneth, C. et al. (1991). Go for English 5è. London: MacMillan. 